\title{
Das Internationale Privatrecht der Transportverträge
}

Die Bestimmung des Beförderungsvertragsstatuts im Spannungsfeld von Art. 5 Rom I-VO und materiellem Einheitstransportrecht

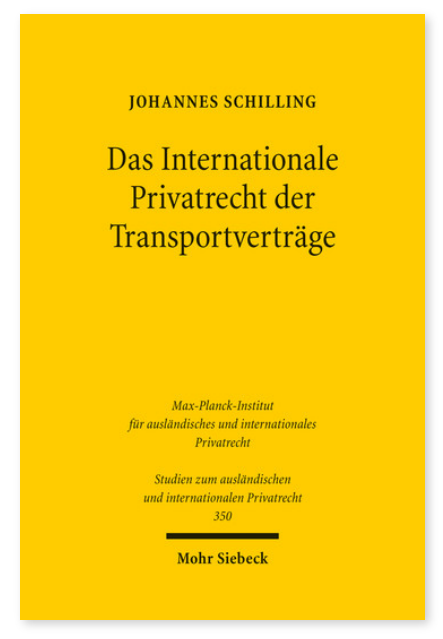

2016. XXXV, 468 Seiten. StudIPR 350

ISBN 978-3-16-154254-1

DOI 10.1628/978-3-16-154254-1

eBook PDF $94,00 €$

ISBN 978-3-16-154253-4

fadengeheftete Broschur 94,00€
Das internationale Transportrecht ist durch eine unübersichtliche Anzahl von materiellen Einheitsrechtsakten gekennzeichnet. Während im Gütertransport die völkerrechtlichen Konventionen, wie die CMR oder das MÜ, zum Tragen kommen, werden bei der Personenbeförderung in erster Linie die europäischen Fahrgastrechteverordnungen relevant. Mittlerweile ist auch das für Beförderungsverträge maßgebliche Kollisionsrecht auf europäischer Ebene vereinheitlicht, und zwar in Art. 5 Rom I-VO.

Angesichts dessen geht Johannes Schilling der Frage nach, welches Recht auf internationale Beförderungsverträge Anwendung findet. Im Fokus stehen dabei sowohl die Auslegung als auch das praktische Anwendungsfeld des neuen europäischen IPR für Beförderungsverträge. Darüber hinaus wird das supranationale Kollisionsrecht zu dem internationalen Einheitsrecht der Güter- und Personenbeförderung ins Verhältnis gesetzt.

Johannes Schilling Geboren 1983; Studium der Rechtswissenschaften an den Universitäten Würzburg, Fribourg $(\mathrm{CH})$ und Poitiers (F); 2008 Erste Juristische Staatsprüfung; Referendariat am Hanseatischen Oberlandesgericht Hamburg; 2015 Zweite Juristische Staatsprüfung; wissenschaftlicher Mitarbeiter am Lehrstuhl für Bürgerliches Recht, Europäisches Wirtschaftsrecht, Internationales Privat- und Prozessrecht sowie Rechtsvergleichung der Universität Würzburg (Prof. Dr. Oliver Remien); Promotionsstipendium der Studienstiftung des Deutschen Volkes; Associate an der IMPRS for Maritime Affairs, Hamburg; wissenschaftlicher Assistent am Max-Planck-Institut für ausländisches und internationales Privatrecht, Hamburg.

Jetzt bestellen:

https://mohrsiebeck.com/buch/das-internationale-privatrecht-der-transportvertraege-9783161542541?no_cache=1 order@mohrsiebeck.com

Telefon: +49 (0)7071-923-17

Telefax: $+49(0) 7071-51104$ 